\title{
TRAINING IN PEDIATRIC ANESTHESIA: A CANADIAN SURVEY
}

Christine A. Vandebeek MBA* ,Robert F. Seal FRCPC $\dagger$, Ramona Kearney FRCPC $\dagger$,Eleanor Reimer FRCPC* ${ }^{*}$,Dilsheesh Purewal MD, J. Mark Ansermino FFA(SA)*

* Department of Anesthesiology, British Columbia's Children's Hospital and University of British Columbia, Vancouver, British Columbia;

$\dagger$ Department of Anesthesiology and Pain Medicine, Stollery Children's Hospital, University of Alberta, Edmonton, Alberta;

INTRODUCTION: Children may comprise $10 \%$ to $15 \%$ of all surgical patients in Canada [1]. Provision of anesthesia care to children is recognized to require special training and expertise [2]. At present, learning objectives for the requisite 3 months of training in pediatric anesthesia are determined at the program level [3]. A survey of pediatric anesthesiologists was conducted to identify current practices in training fellows and residents across Canada.

METHODS: 187 Canadian pediatric anesthesiologists were invited to complete a web survey. Respondents were asked about the level of supervision required for trainees in select difficult pediatric cases and the criteria used to determine whether they were capable of independent practice.

RESULTS: 67 completed surveys were received. In determining whether fellows were capable of independent practice, the strong majority (66\%) relied on the ad hoc opinions of their colleagues to come to a departmental consensus on the competencies the fellow had demonstrated. Another 13\% relied on the consensus of a departmental committee that had been struck to oversee fellowship training. For most training scenarios, the majority of respondents $(50 \%-69 \%)$ felt it was necessary to be in the operating room even while supervising a fellow. Each patient encounter was judged independently. Staff anesthesiologists were present in the operating room most often when a fellow encountered a major trauma (69\%) or a known airway anomaly (64\%) and least often for an uncomplicated case outside regular hours. With respect to resid $\boldsymbol{e} t \mathrm{training}$, respondents showed the most resistance to allowing residents to independently provide anesthesia in a remote location (75\%) or to induce anesthesia for pyloric stenosis (49\%). In deciding whether to allow residents to attempt either of these cases, respondents first considered a resident's pediatric anesthesia experience and then considered patient factors (age, weight and co-morbidities).

DISCUSSION: The survey results also confirm the presence of a wide variation in the criteria for judging competency of residents and fellows in pediatric anesthesia. Defined outcome-based competencies may be one step towards resolving discrepancies among supervisors in identifying relevant training experiences and formalizing their assessment of trainee competency.

\section{REFERENCES:}

1. Canadian Institute for Health Information (CIHI). Day Procedures by Province of Facility Location in 1999. Available from URL; http://secure.cihi.ca/cihiweb/

2. Coté CJ, Notterman DA, Karl HW, Weinberg JA, McCloskey C. Adverse Sedation Events in Pediatrics: A Critical Incident Analysis of Contributing Factors. Ped iutrics 2000;105:805-14.

3. Royal College of Physicians and Surgeons of Canada. Objectives of Training and Specialty Training Requirements 2003 May. Available from URL; http://rcpsc.medical.org/information/ 